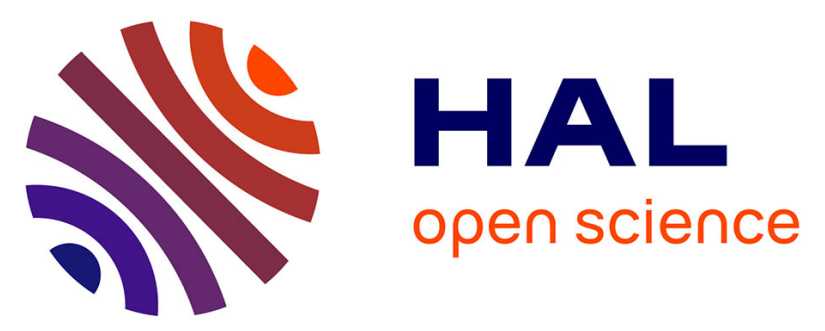

\title{
Alterations of musculoskeletal models for a more accurate estimation of lower limb joint contact forces during normal gait: A systematic review
}

Florent Moissenet, Luca Modenese, Raphaël Dumas

\section{- To cite this version:}

Florent Moissenet, Luca Modenese, Raphaël Dumas. Alterations of musculoskeletal models for a more accurate estimation of lower limb joint contact forces during normal gait: A systematic review. Journal of Biomechanics, 2017, 63, pp.8-20. 10.1016/j.jbiomech.2017.08.025 . hal-01635826v2

\section{HAL Id: hal-01635826 \\ https://hal.science/hal-01635826v2}

Submitted on 13 Feb 2020

HAL is a multi-disciplinary open access archive for the deposit and dissemination of scientific research documents, whether they are published or not. The documents may come from teaching and research institutions in France or abroad, or from public or private research centers.
L'archive ouverte pluridisciplinaire HAL, est destinée au dépôt et à la diffusion de documents scientifiques de niveau recherche, publiés ou non, émanant des établissements d'enseignement et de recherche français ou étrangers, des laboratoires publics ou privés. 


\section{Accepted Manuscript}

Review

Alterations of musculoskeletal models for a more accurate estimation of lower limb joint contact forces during normal gait: a systematic review

F. Moissenet, L. Modenese, R. Dumas

PII:

S0021-9290(17)30447-5

DOI: http://dx.doi.org/10.1016/j.jbiomech.2017.08.025

Reference: BM 8351

To appear in: Journal of Biomechanics

Received Date: $\quad 23$ December 2016

Revised Date: $\quad 27$ June 2017

Accepted Date: $\quad 25$ August 2017

Please cite this article as: F. Moissenet, L. Modenese, R. Dumas, Alterations of musculoskeletal models for a more accurate estimation of lower limb joint contact forces during normal gait: a systematic review, Journal of Biomechanics (2017), doi: http://dx.doi.org/10.1016/j.jbiomech.2017.08.025

This is a PDF file of an unedited manuscript that has been accepted for publication. As a service to our customers we are providing this early version of the manuscript. The manuscript will undergo copyediting, typesetting, and review of the resulting proof before it is published in its final form. Please note that during the production process errors may be discovered which could affect the content, and all legal disclaimers that apply to the journal pertain. 


\title{
Alterations of musculoskeletal models for a more accurate estimation of lower limb joint contact forces during normal gait: a systematic review
}

\section{F. Moissenet ${ }^{1}$, L. Modenese ${ }^{2,3}$, R. Dumas ${ }^{4}$}

${ }^{1}$ Centre National de Rééducation Fonctionnelle et de Réadaptation - Rehazenter, Laboratoire d'Analyse du Mouvement et de la Posture (LAMP), Luxembourg

${ }^{2}$ INSIGNEO Institute for in silico Medicine, University of Sheffield, Sheffield, UK

${ }^{3}$ Department of Mechanical Engineering, University of Sheffield, Sheffield, UK

${ }^{4}$ Univ Lyon, Université Claude Bernard Lyon 1, IFSTTAR, LBMC UMR_T9406, F69622, Lyon, France

\begin{abstract}
Musculoskeletal modelling is a methodology used to investigate joint contact forces during a movement. High accuracy in the estimation of the hip or knee joint contact forces can be obtained with subject-specific models. However, construction of subject-specific models remains time consuming and expensive. The purpose of this systematic review of the literature was to identify what alterations can be made on generic (i.e. literature-based, without any subject-specific measurement other than body size and weight) musculoskeletal models to obtain a better estimation of the joint contact forces. The impact of these alterations on the accuracy of the estimated joint contact forces were appraised.

The systematic search yielded to 141 articles and 24 papers were included in the review. Different strategies of alterations were found: skeletal and joint model (e.g. number of degrees of freedom, knee alignment), muscle model (e.g. Hill-type muscle parameters, level of muscular redundancy), and optimisation problem (e.g. objective function, design variables, constraints). All these alterations had an impact on joint contact force accuracy but it was not possible to highlight any trend defining which alteration had the largest impact.
\end{abstract}


Keywords: survey, joint reaction force, skeletal and joint model, muscle model, optimisation problem, validation

\section{Introduction}

Musculoskeletal modelling is a computational methodology used to investigate musculotendon forces and joint contact forces during a movement, which cannot be easily measured (Chèze et al., 2015; Erdemir et al., 2007; Pandy and Andriacchi, 2010). In particular, recent literature has demonstrated that a high accuracy in the estimation of the hip or tibiofemoral joint contact forces can be obtained, but induced the use of an extensive personalisation of the model parameters (Ding et al., 2016; Gerus et al., 2013; Jung et al., 2016; Kia et al., 2014; Marra et al., 2014). However, the construction of subject-specific models remains a time consuming procedure that requires not always available data, such as medical imaging. Conversely, several components of generic musculoskeletal models may be altered that have noticeable influence on the estimated joint contact forces. Generic models, in this context, refer to original models established only from literature data and not subject-specific measurements. The present review focused on possible alterations of generic musculoskeletal models by assuming that, through a more accurate estimation of joint contact forces, they could reduce the need of model personalisation, and thus facilitate a broader use of musculoskeletal modelling.

Several data repositories have been made available and allow to evaluate model accuracy during different motion tasks. Bergmann et al. (Bergmann et al., 2001) have disseminated in vivo measurements of hip contact forces, obtained through the use of instrumented hip implants, as well as kinematics and ground reaction forces and moments, during several daily activities (e.g. walking at different speeds, up and down stairs, sitting down, standing). 
Similarly, Fregly et al. (Fregly et al., 2012) have disseminated a dataset concerning tibiofemoral medial and lateral contact forces during several variant of walking (e.g. normal, bouncy, medial trust, turn, acceleration). This data repository was completed with medical imaging data allowing the personalisation of a musculoskeletal model. These repositories have already been used in several studies and allowed to evaluate the accuracy of models with different levels of personalisation.

In this study, a systematic literature review was performed in order to identify what are the alterations that can be made on a generic musculoskeletal model to obtain a more accurate estimation of joint contact forces. The impact of these alterations on the accuracy of the estimated forces was appraised. More specifically, this study focused on lower limb musculoskeletal models and on hip and tibiofemoral joint contact forces during normal gait, because these forces have been now extensively validated against the previously mentioned in vivo measurements from instrumented implants.

\section{Material \& Methods}

\subsection{Search strategy}

An electronic search was performed in Medline, Scopus, and Academic Search Premier databases. The logical (nested) expressions for the search were: musc* and contact and ((hip or knee or tibio*femoral) and (force* or load or reaction)) and (((force-measuring or instrumented or force-instrumented) and (replacement or implant or prosthesis)) or (valid* or accura* or in vivo measurement $\left.{ }^{*}\right)$ ) not cadaver*. The search was based on the title, keywords 
and abstract. References cited by the articles remaining after applying the exclusion criteria (see below) were also cross-referenced as well as the articles citing them.

\subsection{Exclusion criteria}

The articles retrieved from the search strategy were reviewed according to the following exclusion criteria. Studies were omitted if they 1) were published only as conference proceedings, 2) were written in a language other than English, 3) did not refer to a generic musculoskeletal model, 4) did not alter a generic musculoskeletal model, 5) did not include validation against instrumented prosthesis measurements, and 6) did not focus on normal gait. Note that the term generic musculoskeletal model refers in this systematic review to a model established only from literature data. It is the baseline situation in all included studies of this systematic review. However, body size and weight may have been personalised for scaling purposes. Moreover, depending on the study, the related generic musculoskeletal model can be different in terms of modelling approach and level of details.

\subsection{Quality assessment}

A customised checklist was developed on the basis of previous reviews in the field of biomechanics addressing connected topics (Kainz et al., 2015; Peters et al., 2010) to assess the methodological quality of the selected studies. Each question was rated two (satisfying description or justification), one (limited details) or zero (no information). The 16-item quality checklist used in this review was: Q1: Are the research objectives clearly stated? Q2: Is the study design clearly described? Q3: Is the scientific context clearly explained? Q4: Is the musculoskeletal model adequately described? Q5: Were the model alterations clearly 
described? Q6: Is the model for joint contact force estimation adequately described? Q7: Were participant characteristics adequately described? Q8: Were movement tasks, equipment design, and set up clearly defined? Q9: Were the evaluation strategy appropriately justified? Q10: Were the analytical methods clearly described? Q11: Were the statistical methods justified and appropriately described (other than descriptive statistics)? Q12: Were the direct results easily interpretable? Q13: Were the main outcomes clearly stated and supported by the results? Q14: Were the limitations of the study clearly described? Q15: Were key findings supported by other literature? Q16: Were conclusions drawn from the study clearly stated? Each study was evaluated independently by the three authors (FM, LM, and RD) for this assessment. In case of discrepancy, the original article was checked to ensure the correct coding, and a consensus was found between authors.

\subsection{Data extraction}

A customised data extraction form was developed to extract key details from each selected study. One author (FM) performed the data extraction and the two other authors (LM and RD) checked the final form to ensure reliability. The retained information consisted in: 1) the investigated joint (i.e. hip joint or tibiofemoral joint), 2) the definition of the generic musculoskeletal model (i.e. software used in the simulations, original model, number of degrees of freedom (DoFs) and of muscular lines of action, muscle paths (i.e. straight lines, via points, wrapping surfaces), method used to solve the muscle redundancy problem and joint contact model), 3) the validation dataset used to assess model accuracy, 4) the alterations applied to the model, and 5) their impact on the joint contact force accuracy. These themes were chosen to provide an overview of the methods of each selected study together with the presented alterations and associated results. When the methods were only partially described 
in the original article, comprehensive information was retrieved from references and author's previous works to provide comparable data across the selected studies.

\section{Results}

\subsection{Search strategy yield}

The search strategy allowed to identify 99 articles in Medline, 65 in Scopus, and 77 in Academic Search Premier, yielding to 141 articles without any duplicate (Fig. 1). According to the exclusion criteria, 20 articles were retained. Most of the excluded articles did not include validation against in vivo measurements from instrumented prosthesis. Others presented either a fully subject-specific musculoskeletal model (Ding et al., 2016; Gerus et al., 2013; Jung et al., 2016; Kia et al., 2014) or a generic musculoskeletal model without alteration (Heller et al., 2001; Kim et al., 2009; Modenese and Phillips, 2012; Purevsuren et al., 2016; Stansfield et al., 2003; Trepczynski et al., 2012). Four more articles were obtained by cross-referencing (Dumas et al., 2012; Lund et al., 2015; Manal and Buchanan, 2013; Steele et al., 2012), yielding the final set of 24 articles. Note that this final set was only composed of rigid body musculoskeletal models (some of them including deformable joints), while both rigid body and finite element musculoskeletal models were initially included.

Quality assessment and data extraction results are reported below. Details can be found in Table S1 (available as supplementary material) and Table 1, respectively.

\subsection{Quality assessment}


The overall score of each article was thus calculated by the sum of rated questions divided by the sum of applicable questions. The selected studies were all of high quality, with a scoring ranged between $80 \%$ and $100 \%$, and a mean score of $92 \%$ (Table S1, available as supplementary material). However, several questions were only partially answered. For example, validation (or comparison with validation dataset) was not always explicitly mentioned as an objective (or a method), elements of the methods (i.e. the musculoskeletal model, computation method for joint contact forces, or the validation dataset) were described just through a reference to previous work, or limitations of the study were not clearly stated or omitted. Only 3 of the 24 selected studies (see Table 1) reported a statistical method other than descriptive statistics (i.e. mean, standard deviation, root mean square error, correlation).

\subsection{Generic musculoskeletal models}

More than half of the studies (13 out of 24) were based on specialised biomechanical software such as Opensim (Delp et al., 2007) and Anybody (Damsgaard et al., 2006). Six studies used Matlab (The Mathworks, USA) to perform the computations. Finally, SIMM (Motion Analysis Corporation, Musculographics, USA), ADAMS (MSC Software, USA) or custommade software were used in the remaining studies.

More than half of the selected studies (13 out of 24) used models based on the generic musculoskeletal model of Delp et al. (Delp, 1990). The original or a variant of the model developed by Klein Horsman et al. (Klein Horsman et al., 2007) or by Arnold et al. (Arnold et al., 2010) were also used. Two further models were also developed by other authors (Heller et al., 2005, 2001; Lin et al., 2010). 
The number of DoFs was related to the generic musculoskeletal model used in each study. Briefly, the primary differences were observed at the hip, tibiofemoral, and patellofemoral joints were the number of DoFs were 3 or 6,1 or 6 , and 0,1 or 6 , respectively.

The number lines of action were also related to the generic musculoskeletal model used in each study and ranged between 11 (Lin et al., 2010) and 163 (Chen et al., 2014; Modenese et al., 2013, 2011; Moissenet et al., 2016; Zhang et al., 2015). In all the selected studies, the muscle paths were enhanced by via points only (15) or with (9) the use of wrapping surfaces. A majority of studies (17 out of 24) solved the muscle redundancy problem (also called the force distribution problem (Crowninshield and Brand, 1981)) through an inverse dynamicsbased optimisation, while some others used a forward dynamics-based optimisation (Guess et al., 2014), an EMG-driven method (Manal and Buchanan, 2013), a reduction method (Lundberg et al., 2013, 2012), computed muscle control method (Hast and Piazza, 2013; Thelen et al., 2014), or a mixed approach (Walter et al., 2014). Proposed objective functions included the sum of muscle activations, or musculo-tendon forces, at different power, both weighted and not. Some studies included additional terms to the objective function, such as reserve actuators (Modenese et al., 2013; Serrancoli et al., 2016) or joint loads (Demers et al., 2014; Lin et al., 2010; Moissenet et al., 2016, 2014). In one study, a min-max method was applied on musculo-tendon forces (Chen et al., 2014). Other objective functions (Manal and Buchanan, 2013; Walter et al., 2014) were mainly based on the tracking of a set of variables (e.g. joint moments).

The computation of joint contact forces was mainly based on 1-point or 2-point rigid contact models (respectively 10 and 5 out of 24 studies). However, several studies introduced deformable structures by using a force dependent kinematics method (Chen et al., 2014; Zhang et al., 2015), a deformable contact with viscous damping (Guess et al., 2014), a rigid body spring model (Hast and Piazza, 2013), or a surrogate contact modelling (Lin et al., 
2010). Some other studies are based on regression equations converting the varus-valgus moment to medial and lateral tibiofemoral contact forces (Lundberg et al., 2013, 2012), or on prosthesis calibration (Serrancoli et al., 2016; Walter et al., 2014).

\subsection{Validation datasets}

Among the 24 selected studies, 19 were interested in particular in the tibiofemoral joint, and 5 in the hip joint. The validation datasets used in these studies are directly related to the joint of interest.

In most of the selected studies, in vivo measurements of hip contact forces were obtained from the HIP98 dataset (Bergmann et al., 2001), while tibiofemoral joint from the six editions of the Grand Challenge Competition to Predict In Vivo Knee Loads (Fregly et al., 2012). In one study, the HIP98 dataset was pooled into a "typical patient" (Heller et al., 2005). In two studies (Lin et al., 2010; Lundberg et al., 2012), the datasets associated with the studies published by Zhao et al. (Zhao et al., 2007) and Mündermann et al. (Mündermann et al., 2008) were used.

\subsection{Alterations of the generic musculoskeletal model}

Three types of alterations of the generic musculoskeletal model have been proposed in the selected studies: 1) skeletal and joint models, 2) muscle model, and 3) optimisation problem. Details are given below.

\subsubsection{Skeletal and joint models}


Alterations of the skeletal and joint models concern kinematics and/or dynamics, and can be divided in nine sub-group: markers' placement (Lund et al., 2015; Navacchia et al., 2016), number of DoFs (Dumas et al., 2012; Lundberg et al., 2013), knee alignment (Lerner et al., 2015; Navacchia et al., 2016; Thelen et al., 2014), femoral anteversion (Heller et al., 2001), scaling strategy (Chen et al., 2014; Lund et al., 2015), medial-lateral tibiofemoral contact forces ratio (Lundberg et al., 2013), inertial parameters (Navacchia et al., 2016), contact points (Lerner et al., 2015; Manal and Buchanan, 2013), contact stiffness (Chen et al., 2014; Zhang et al., 2015), and joint passive stiffness (Dumas et al., 2012; Lundberg et al., 2013).

\subsubsection{Muscle model}

Several studies also altered the muscle model by introducing some variations in: muscle geometry (i.e. insertion sites, muscle path) (Navacchia et al., 2016; Zhang et al., 2015), Hilltype muscle parameters (e.g. optimal fibre length, tendon slack length, pennation angle, EMG-driven model parameters) (Manal and Buchanan, 2013; Navacchia et al., 2016; Serrancoli et al., 2016), or level of muscular redundancy (i.e. number of lines of action) (Heller et al., 2005; Moissenet et al., 2016).

\subsubsection{Optimisation problem}

Five studies altered the objective function of the optimisation problem by modifying the objective function (Chen et al., 2014; Modenese et al., 2011; Zhang et al., 2015), or the optimisation weights (Knarr and Higginson, 2015; Steele et al., 2012). Four studies altered the design variables by introducing in the optimisation problem: joint contact forces (Demers et al., 2014; Lin et al., 2010; Modenese et al., 2013; Moissenet et al., 2014), ligament and bone 
forces (Moissenet et al., 2014), or reserve actuators (Modenese et al., 2013) instead of only muscle activations or musculo-tendon forces. Three studies altered the optimisation constraints by modifying the boundaries of design variables (Hast and Piazza, 2013; Knarr and Higginson, 2015) or by introducing additional constraints (e.g. residual loads acting on the tibia) (Lin et al., 2010). Other cases concerned the alteration of PID gains in a forward dynamics-based optimisation (Guess et al., 2014) and the use of EMG synergies (Walter et al., 2014).

\subsection{Level of evidence}

All the alterations proposed in the selected studies had an impact on joint contact force accuracy. However, the present review did not allow to highlight any trend defining which alteration has the largest potential to improve accuracy. Moreover, the evidence of this impact highly varied between studies, and could be divided in four categories. The first category corresponded to studies providing quantitative evidence with statistics (e.g. t-test, ANOVA, 95\% confidence interval, Monte Carlo simulation) (Lerner et al., 2015; Lund et al., 2015; Serrancoli et al., 2016). In these studies, results related to accuracy were reported using the root mean square errors (RMSE) between the measured and estimated joint contact forces, expressed in Newton or in body weight (BW) (to ease comparison, all data have been expressed in BW in Table 1). The second category corresponded to studies providing quantitative evidence with only descriptive statistics (Demers et al., 2014; Heller et al., 2005, 2001; Knarr and Higginson, 2015; Lin et al., 2010; Lundberg et al., 2013, 2012; Manal and Buchanan, 2013; Modenese et al., 2013, 2011, Moissenet et al., 2016, 2014; Walter et al., 2014). In most of these studies, results related to accuracy were reported using the root mean square error (RMSE) between the measured and estimated joint contact forces. The third 
category corresponded to studies providing only a partial quantitative evidence. Two cases could be listed in this category. Firstly, only RMSE between baseline and altered joint contact forces was given (Chen et al., 2014; Zhang et al., 2015). Secondly, only quantitative evidence on accuracy at baseline or after alterations was given (Navacchia et al., 2016; Steele et al., 2012; Thelen et al., 2014). In both cases, the results highlighted the alteration impact on accuracy, but do not quantify it. The last category corresponded to studies providing no quantitative evidence (Dumas et al., 2012; Guess et al., 2014; Hast and Piazza, 2013). In this case, results related to accuracy were presented in figures, leading to an approximate interpretation of accuracy.

\subsection{Impact of the alterations on joint contact force accuracy}

On the whole, by merging all reported quantitative data before alteration (16 out 24 studies), the range of RMSE at baseline (between estimated and measured joint contact forces) extracted from the selected studies providing this value was $0.17-1.39 \mathrm{BW}$ for the tibiofemoral medial contact force, $0.18-0.81 \mathrm{BW}$ for the tibiofemoral lateral contact force, $0.30-0.88 \mathrm{BW}$ for the tibiofemoral total contact force, and $0.45-0.59 \mathrm{BW}$ for the hip contact force (Figure 2 and Figure 3: some ranges may differ with these figures where only studies providing baseline and alterations RMSE were reported). After alterations (13 out of 24 studies), the range of RMSE was $0.08-0.50 \mathrm{BW}$ for the tibiofemoral medial contact force, $0.09-0.63 \mathrm{BW}$ for the tibiofemoral lateral contact force, $0.15-0.77 \mathrm{BW}$ for the tibiofemoral total contact force, and $0.18-4.52 \mathrm{BW}$ for the hip contact force (Figure 2 and Figure 3 ). At the hip joint, the use of high power in the objective function had a negative impact on the upper bound of accuracy (Figure 3). At the knee joint, instead, both the minimum and maximum RMSE were decreased for each evaluated contact force component. Moreover, 
unsurprisingly, the minimum RMSE was obtained when tracking the measured tibiofemoral joint contact forces (Serrancoli et al., 2016; Walter et al., 2014) by reaching a value of 0.08 $\mathrm{BW}, 0.09 \mathrm{BW}$, and $0.15 \mathrm{BW}$, respectively for the tibiofemoral medial, lateral and total contact forces (Figure 2). It must also be noticed that some alterations mainly have an impact on the medial-lateral tibiofemoral contact forces ratio, with only slight variations on the total contact force accuracy (Moissenet et al., 2016; Thelen et al., 2014).

\section{Discussion}

\subsection{Accuracy assessment}

The way the joint contact force accuracy was assessed varies between studies, leading to different levels of interpretation. Firstly, the alterations could be simply applied (Demers et al., 2014; Dumas et al., 2012; Guess et al., 2014; Hast and Piazza, 2013; Heller et al., 2005, 2001; Knarr and Higginson, 2015; Lerner et al., 2015; Lin et al., 2010; Lund et al., 2015; Lundberg et al., 2013; Manal and Buchanan, 2013; Modenese et al., 2013, 2011, Moissenet et al., 2016, 2014; Serrancoli et al., 2016; Steele et al., 2012; Thelen et al., 2014; Walter et al., 2014) or explored through a sensitivity analysis (Chen et al., 2014; Lundberg et al., 2012; Navacchia et al., 2016; Zhang et al., 2015). Secondly, it has been showed that the provided level of evidence varied between studies. This was mainly due to differences in the generic musculoskeletal model and in the type of alteration. Indeed, results clearly show that the baseline situation of most of the studies is different, with various modelling approaches $(e . g$. computation of joint contact forces based on one-point rigid contact model versus deformable contact with viscous damping model) and different levels of details (e.g. number lines of action varying between 11 and 163). Thirdly, the units of the error metric used to report joint 
contact forces accuracy also differed between studies (e.g. Newton, BW, percents). Even if RMSE expressed in BW has been used in several works, a consensual methodology would have eased the comparison.

\subsection{Strategies of alteration}

With some exceptions, most of the strategies of alteration could be gathered in two categories in the selected studies.

On one hand, alterations could have a substantial impact on the model lever arms. This could be done by tuning the position and orientation of joint centres and segmental coordinate systems (e.g. indirectly through markers' placement (Lund et al., 2015; Navacchia et al., 2016)). Another option was to modify the position of the contact points by tuning the knee alignment (Lerner et al., 2015; Navacchia et al., 2016; Thelen et al., 2014), or the mediallateral position of contact points (Lerner et al., 2015; Manal and Buchanan, 2013). In the context of a multi-contact joint (e.g. tibiofemoral joint), the lever arms of joint contact forces was then modified, and thus the repartition of forces between contact points. A third possibility was to modify the muscular geometry by tuning the skeletal geometry (e.g. femoral anteversion (Heller et al., 2001)), or directly the muscular geometry (e.g. insertion sites, muscle path (Navacchia et al., 2016; Zhang et al., 2015)). The muscular lever arms were then directly affected, leading to new estimations of musculo-tendon forces and thus joint contact forces.

On the other hand, alterations could have a substantial impact on the distribution of musculotendon forces (i.e. on the solution of the muscular redundancy problem). This could first be done by modifying the number of DoFs (Dumas et al., 2012; Lundberg et al., 2013). Indeed, increasing the number of DoFs may results in the recruitment of muscle aiming to stabilise the 
altered joint (Jinha et al., 2006). The sum of musculo-tendon forces related to this joint may thus be increased, leading to a higher joint contact force (Dumas et al., 2012). The muscular redundancy also played a key role in the distribution of musculo-tendon forces (Heller et al., 2005; Moissenet et al., 2016). By increasing the number of muscular lines of action, the load may be shared by several musculo-tendon units with different lever arms, and thus impact joint contact forces. Finally, the way the optimisation problem was defined had a substantial impact on the force sharing problem. By altering the objective function (Chen et al., 2014; Knarr and Higginson, 2015; Modenese et al., 2011; Steele et al., 2012; Zhang et al., 2015), the design variables (Demers et al., 2014; Lin et al., 2010; Modenese et al., 2013; Moissenet et al., 2014), or the optimisation constraints (Hast and Piazza, 2013; Knarr and Higginson, 2015; Lin et al., 2010), the way the muscles were recruited varied and generated different musculotendon forces amplitudes and patterns. This could be explained by the fact that these alterations modified the solution space of the optimisation problem, allowing the identification of new optimal solutions.

\subsection{Limitations}

The present systematic review was limited to studies exploring only lower limb musculoskeletal models during normal gait, where joint contact estimations were validated against instrumented prosthesis measurements. Several types of musculoskeletal model may thus have been omitted. This was for example the case for finite element models (e.g. Adouni et al., 2016; Beillas et al., 2004; Marouane et al., 2017, 2016) for whose no study was found with validation against instrumented prosthesis measurements. Similarly, several alterations may thus have been omitted. This was for example the case for the study of Smith et al. (Smith et al., 2016), studying modified styles of gait (i.e. smooth and bouncy), where a variant 
of the Arnold et al. model (Arnold et al., 2010) was used in an inverse dynamics-based optimisation to evaluate the impact of alterations on knee alignment and knee ligament stiffness on tibiofemoral joint contact forces accuracy. It was also interesting to note that the studies using subject-specific musculoskeletal models, excluded from this review, specifically personalised the following items: the bone geometry and the origin and insertion of muscle line of actions (Ding et al., 2016; Gerus et al., 2013; Jung et al., 2016; Kia et al., 2014; Marra et al., 2014), the joint kinematics (i.e. coupling curves between de DoFs) (Gerus et al., 2013), and the joint geometry (i.e. prosthesis design) when deformable joint was introduced (Jung et al., 2016; Kia et al., 2014; Marra et al., 2014).

\section{Conclusion}

Musculoskeletal modelling is a computational methodology which involves determination of a large number of parameters and several implementation choices. With the objective of a more accurate estimation of the joint contact forces, some of these parameters, typically defining the joint and muscle geometries, have been personalised using medical imaging. According to this systematic review, many of these model parameters and implementation choices have been also altered from a generic musculoskeletal model, e.g. number of degrees of freedom, muscle parameters, level of muscular redundancy, objective function, constraints, etc. All these alterations had an impact on the accuracy of the hip and tibiofemoral joint contact forces, so demonstrating the potential for improving model prediction without necessarily involving costly and time consuming medical images. However, due to discrepancies in the reported evidence about this impact and despite a high quality of the reviewed studies, it was not possible to highlight any trend defining which alteration had the largest impact. If results of future studies implementing model alterations will be reported with consistent metrics and level of evidence, it might be possible to identify specific 
modelling features that, if personalised, will lead to an increased accuracy in the estimation of joint contact forces in the lower limb.

\section{Conflict of interest}

The authors declare that the study did not raise any conflict of interest.

\section{References}

Adouni, M., Shirazi-Adl, A., Marouane, H., 2016. Role of gastrocnemius activation in knee joint biomechanics: gastrocnemius acts as an ACL antagonist. Comput. Methods Biomech. Biomed. Engin. 19, 376-385. doi:10.1080/10255842.2015.1032943

Arnold, E.M., Ward, S.R., Lieber, R.L., Delp, S.L., 2010. A model of the lower limb for analysis of human movement. Ann. Biomed. Eng. 38, 269-279. doi:10.1007/s10439009-9852-5

Beillas, P., Papaioannou, G., Tashman, S., Yang, K.., 2004. A new method to investigate in vivo knee behavior using a finite element model of the lower limb. J. Biomech. 37, 1019-1030. doi:10.1016/j.jbiomech.2003.11.022

Bergmann, G., Deuretzbacher, G., Heller, M., Graichen, F., Rohlmann, A., Strauss, J., Duda, G.N., 2001. Hip contact forces and gait patterns from routine activities. J. Biomech. 34, 859-871.

Chen, Z., Zhang, X., Ardestani, M.M., Wang, L., Liu, Y., Lian, Q., He, J., Li, D., Jin, Z., 2014. Prediction of in vivo joint mechanics of an artificial knee implant using rigid multi-body dynamics with elastic contacts. Proc. Inst. Mech. Eng. [H] 1-12. doi: $10.1177 / 0954411914537476$

Chèze, L., Moissenet, F., Dumas, R., 2015. State of the art and current limits of musculoskeletal models for clinical applications. Mov. Sport Sci. - Sci. Mot. 90, 7-17. doi: $10.1051 / \mathrm{sm} / 2012026$

Crowninshield, R.D., Brand, R.A., 1981. A physiologically based criterion of muscle force prediction in locomotion. J. Biomech. 14, 793-801.

Damsgaard, M., Rasmussen, J., Christensen, S.T., Surma, E., de Zee, M., 2006. Analysis of musculoskeletal systems in the AnyBody Modeling System. Simul. Model. Pract. Theory 14, 1100-1111. doi:10.1016/j.simpat.2006.09.001

Delp, S.L., 1990. An interactive graphics-based model of the lower extremity to study orthopeadic surgery procedures. IEEE Trans. Biomed. Eng. 37, 757-767.

Delp, S.L., Anderson, F.C., Arnold, A.S., Loan, P., Habib, A., John, C.T., Guendelman, E., Thelen, D.G., 2007. OpenSim: Open-source software to create and analyze dynamic simulations of movement. IEEE Trans. Biomed. Eng. 54, 1940-1950. doi:10.1109/TBME.2007.901024

Demers, M.S., Pal, S., Delp, S.L., 2014. Changes in Tibiofemoral Forces due to Variations in Muscle Activity during Walking. J. Orthop. Res. 32, 769-776. doi:10.1002/jor.22601

Ding, Z., Nolte, D., Kit Tsang, C., Cleather, D.J., Kedgley, A.E., Bull, A.M.J., 2016. In Vivo Knee Contact Force Prediction Using Patient-Specific Musculoskeletal Geometry in a Segment-Based Computational Model. J. Biomech. Eng. 138, 21018. doi: $10.1115 / 1.4032412$ 
Dumas, R., Moissenet, F., Gasparutto, X., Chèze, L., 2012. Influence of joint models on lower-limb musculo-tendon forces and three-dimensional joint reaction forces during gait. Proc. Inst. Mech. Eng. [H] 226, 146-160. doi:10.1177/0954411911431396

Erdemir, A., McLean, S.., Herzog, W., Van Den Bogert, A.J., 2007. Model-based estimation of muscle forces exerted during movements. Clin. Biomech. 22, 131-54. doi: 10.1016/j.clinbiomech.2006.09.005

Fregly, B.J., Besier, T.F., Lloyd, D.G., Delp, S.L., Banks, S.A., Pandy, M.G., D’Lima, D.D., 2012. Grand challenge competition to predict in vivo knee loads. J. Orthop. Res. Off. Publ. Orthop. Res. Soc. 30, 503-513.

Gerus, P., Sartori, M., Besier, T.F., Fregly, B.J., Delp, S.L., Banks, S.A., Pandy, M.G., D'Lima, D.D., Lloyd, D.G., 2013. Subject-specific knee joint geometry improves predictions of medial tibiofemoral contact forces. J. Biomech. 46, 2778-2786.

Guess, T.M., Stylianou, A.P., Kia, M., 2014. Concurrent Prediction of Muscle and Tibiofemoral Contact Forces During Treadmill Gait. J. Biomech. Eng. 136, 1-9. doi: $10.1115 / 1.4026359$

Hast, M.W., Piazza, S.J., 2013. Dual-joint modeling for estimation of total knee replacement contact forces during locomotion. J. Biomech. Eng. 135, 021013. doi: $10.1115 / 1.4023320$

Heller, M.O., Bergmann, G., Deuretzbacher, G., Claes, L., Haas, N.P., Duda, G.N., 2001. Influence of femoral anteversion on proximal femoral loading: measurement and simulation in four patients. Clin. Biomech. 16, 644-649.

Heller, M.O., Bergmann, G., Kassi, J.-P., Claes, L., Haas, N.P., Duda, G.N., 2005. Determination of muscle loading at the hip joint for use in pre-clinical testing. J. Biomech. 38, 1155-1163. doi:10.1016/j.jbiomech.2004.05.022

Jinha, A., Ait-Haddou, R., Herzog, W., 2006. Predictions of co-contraction depend critically on degrees-of-freedom in the musculoskeletal model. J. Biomech. 39, 1145-1152. doi:10.1016/j.jbiomech.2005.03.001

Jung, Y., Phan, C.-B., Koo, S., 2016. Intra-articular Knee Contact Force Estimation during Walking using Force-reaction Elements and Subject-specific Joint Model. J. Biomech. Eng. 138, 1-9. doi:10.1115/1.4032414

Kainz, H., Carty, C.P., Modenese, L., Boyd, R.N., Lloyd, D.G., 2015. Estimation of the hip joint centre in human motion analysis: A systematic review. Clin. Biomech. 30, 319329. doi:10.1016/j.clinbiomech.2015.02.005

Kia, M., Stylianou, A.P., Guess, T.M., 2014. Evaluation of a Musculoskeletal Model with Prosthetic Knee through Six Experimental Gait Trials. Med. Eng. Phys. 33, 395-401. doi:10.1038/nbt.3121.ChIP-nexus

Kim, H.J., Fernandez, J.W., Akbarshahi, M., Walter, J.P., Fregly, B.J., Pandy, M.G., 2009. Evaluation of predicted knee-joint muscle forces during gait using an instrumented knee implant. J. Orthop. Res. 27, 1326-1331.

Klein Horsman, M.D., Koopman, H.F.J.M., van der Helm, F.C.T., Prosé, L.P., Veeger, H.E.J., 2007. Morphological muscle and joint parameters for musculoskeletal modelling of the lower extremity. Clin. Biomech. Bristol Avon 22, 239-247.

Knarr, B.A., Higginson, J.S., 2015. Practical approach to subject-specific estimation of knee joint contact force. J. Biomech. 48, 2897-2902. doi:10.1016/j.jbiomech.2015.04.020

Lerner, Z.F., DeMers, M.S., Delp, S.L., Browning, R.C., 2015. How tibiofemoral alignment and contact locations affect predictions of medial and lateral tibiofemoral contact forces. J. Biomech. 48, 644-650.

Lin, Y.-C., Walter, J.P., Banks, S.A., Pandy, M.G., Fregly, B.J., 2010. Simultaneous prediction of muscle and contact forces in the knee during gait. J. Biomech. 43, 945952. 
Lund, M.E., Andersen, M.S., de Zee, M., Rasmussen, J., 2015. Scaling of musculoskeletal models from static and dynamic trials. Int. Biomech. 2, 1-11. doi:10.1080/23335432.2014.993706

Lundberg, H.J., Foucher, K.C., Andriacchi, T.P., Wimmer, M.A., 2012. Direct comparison of measured and calculated total knee replacement force envelopes during walking in the presence of normal and abnormal gait patterns. J. Biomech. 45, 990-996. doi:10.1016/j.jbiomech.2012.01.015

Lundberg, H.J., Knowlton, C., Wimmer, M.A., 2013. Fine tuning total knee replacement contact force prediction algorithms using blinded model validation. J. Biomech. Eng. 135, 1-9. doi:10.1115/1.4023388

Manal, K., Buchanan, T.S., 2013. An electromyogram-driven musculoskeletal model of the knee to predict in vivo joint contact forces during normal and novel gait patterns. J. Biomech. Eng. 135, 21014. doi:10.1115/1.4023457

Marouane, H., Shirazi-Adl, A., Adouni, M., 2017. 3D active-passive response of human knee joint in gait is markedly altered when simulated as a planar 2D joint. Biomech. Model. Mechanobiol. 16, 693-703. doi:10.1007/s10237-016-0846-6

Marouane, H., Shirazi-Adl, A., Adouni, M., 2016. Alterations in knee contact forces and centers in stance phase of gait: A detailed lower extremity musculoskeletal model. J. Biomech. 49, 185-192. doi:10.1016/j.jbiomech.2015.12.016

Marra, M.A., Vanheule, V., Fluit, R., Koopman, B.H.F.J.M., Rasmussen, J., Verdonschot, N.J.J., Andersen, M.S., 2014. A Subject-Specific Musculoskeletal Modeling Framework to Predict in Vivo Mechanics of Total Knee Arthroplasty. J. Biomech. Eng. 137, 20904. doi:10.1115/1.4029258

Modenese, L., Gopalakrishnan, A., Phillips, A.T.M., 2013. Application of a falsification strategy to a musculoskeletal model of the lower limb and accuracy of the predicted hip contact force vector. J. Biomech. 46, 1193-1200. doi:10.1016/j.jbiomech.2012.11.045

Modenese, L., Phillips, A.T.M., 2012. Prediction of hip contact forces and muscle activations during walking at different speeds. Multibody Syst. Dyn. 28, 157-168. doi:10.1007/s11044-011-9274-7

Modenese, L., Phillips, A.T.M., Bull, A.M.J., 2011. An open source lower limb model: Hip joint validation. J. Biomech. 44, 2185-2193.

Moissenet, F., Chèze, L., Dumas, R., 2016. Influence of the level of muscular redundancy on the validity of a musculoskeletal model. J. Biomech. Eng. 138. doi:10.1115/1.4032127

Moissenet, F., Chèze, L., Dumas, R., 2014. A 3D lower limb musculoskeletal model for simultaneous estimation of musculo-tendon, joint contact, ligament and bone forces during gait. J. Biomech. 47, 50-58. doi:10.1016/j.jbiomech.2013.10.015

Mündermann, A., Dyrby, C.O., D’Lima, D.D., Colwell, C.W., Andriacchi, T.P., 2008. In vivo knee loading characteristics during activities of daily living as measured by an instrumented total knee replacement. J. Orthop. Res. 26, 1167-1172. doi:10.1002/jor.20655

Navacchia, A., Myers, C.A., Rullkoetter, P.J., Shelburne, K.B., 2016. Prediction of In Vivo Knee Joint Loads Using a Global Probabilistic Analysis. J. Biomech. Eng. 138, 1-12. doi: $10.1115 / 1.4032379$

Pandy, M.G., Andriacchi, T.P., 2010. Muscle and joint function in human locomotion. Annu. Rev. Biomed. Eng. 12, 401-433. doi:10.1146/annurev-bioeng-070909-105259

Peters, A., Galna, B., Sangeux, M., Morris, M., Baker, R., 2010. Quantification of soft tissue artifact in lower limb human motion analysis: A systematic review. Gait Posture 31, 1-8. doi:10.1016/j.gaitpost.2009.09.004 
Purevsuren, T., Dorj, A., Kim, K., Kim, Y.H., 2016. Prediction of medial and lateral contact force of the knee joint during normal and turning gait after total knee replacement. Proc. Inst. Mech. Eng. [H] 230, 288-297.

Serrancoli, G., Kinney, A.L., Fregly, B.J., Font-llagunes, J.M., 2016. Neuromusculoskeletal Model Calibration Significantly Affects Predicted Knee Contact Forces for Walking. J. Biomech. Eng. 138, 1-11. doi:10.1115/1.4033673

Smith, C.R., Vignos, M.F., Lenhart, R.L., Kaiser, J., Thelen, D.G., 2016. The Influence of Component Alignment and Ligament Properties on Tibiofemoral Contact Forces in Total Knee Replacement. J. Biomech. Eng. 138, 1-10. doi:10.1115/1.4032464

Stansfield, B.W., Nicol, A.C., Paul, J.P., Kelly, I.G., Graichen, F., Bergmann, G., 2003. Direct comparison of calculated hip joint contact forces with those measured using instrumented implants. An evaluation of a three-dimensional mathematical model of the lower limb. J. Biomech. 36, 929-936.

Steele, K.M., Demers, M.S., Schwartz, M.H., Delp, S.L., 2012. Compressive tibiofemoral force during crouch gait. Gait Posture Posture 35, 556-560. doi:10.1016/j.gaitpost.2011.11.023

Thelen, D.G., Choi, K.W., Schmitz, A.M., 2014. Co-Simulation of Neuromuscular Dynamics and Knee Mechanics During Human Walking. J. Biomech. Eng. 136, 1-8. doi:10.1115/1.4026358

Trepczynski, A., Kutzner, I., Kornaropoulos, E., Taylor, W.R., Duda, G.N., Bergmann, G., Heller, M.O., 2012. Patellofemoral joint contact forces during activities with high knee flexion. J. Orthop. Res. 408-415. doi:10.1002/jor.21540

Walter, J.P., Kinney, A.L., Banks, S.A., Besier, T.F., Lloyd, D.G., Fregly, B.J., 2014. Muscle Synergies May Improve Optimization Prediction of Knee Contact Forces During Walking. J. Biomech. Eng. 136, 1-9. doi:10.1115/1.4026428

Zhang, X., Chen, Z., Wang, L., Yang, W., Li, D., Jin, Z., 2015. Prediction of hip joint load and translation using musculoskeletal modelling with force-dependent kinematics and experimental validation. Proc. Inst. Mech. Eng. $[\mathrm{H}]$ 229, 477-490. doi:10.1177/0954411915589115

Zhao, D., Banks, S.A., D’Lima, D.D., Colwell, C.W., Fregly, B.J., 2007. In Vivo Medial and Lateral Tibial Loads during Dynamic and High Flexion Activities Dong. J. Orthop. Res. 25, 593-602. 


\section{Tables and figures captions}

Table 1: Overview of selected studies including generic musculoskeletal model, validation dataset, model alterations, available statistics (other than descriptive), and impact of the alterations on joint contact force accuracy.

Figure 1: Flowchart of the search strategy conducted in this review.

Figure 2: Mean errors on tibiofemoral medial, lateral and total contact forces between baseline and alterations. See Table 1 for the numbering of the alterations.

Figure 3: Mean errors on hip contact forces between baseline and alterations. See Table 1 for the numbering of the alterations. 


\section{Table 1}

A/P: Anterior-posterior, BW: Body weight, DoF: Degree of freedom, F/E: Flexion-extension, I/E: Internal-external rotation, PF: Patellofemoral, PID: Proportional integral derivative, R2: Determination coefficient, RMSE: Root mean square error, TF: tibiofemoral, VH: Visible human

\begin{tabular}{|c|c|c|c|c|c|}
\hline Article & Joint & Generic musculoskeletal model & Validation dataset & Model alterations & $\begin{array}{l}\text { Impact of the alterations on joint contact force } \\
\text { accuracy }\end{array}$ \\
\hline $\begin{array}{l}\text { Chen et al. } \\
\text { (2014) }\end{array}$ & $\mathrm{TF}$ & $\begin{array}{l}\text { Software: Anybody } \\
\text { Model: Variant of the Klein Horsman et al. (2007) model } \\
\text { DoFs: } 6 \text { pelvis, } 3 \text { hip, } 1 \mathrm{TF}, 1 \text { ankle, } 1 \text { subtalar } \\
\text { Muscular lines of action: } 163 \text { per leg } \\
\text { Muscle path: Via points and wrapping surfaces } \\
\text { Optimisation: Inverse dynamics-based optimisation } \\
\text { Objective function: Min-max muscle recruitment } \\
\text { Joint contact model: Force dependent kinematic (Andersen \& } \\
\text { Rasmusen 2011) }\end{array}$ & $\begin{array}{l}\text { Third edition data of } \\
\text { the Grand Challenge } \\
\text { Competition to Predict } \\
\text { In Vivo Knee Loads } \\
\text { (Fregly et al., 2012) }\end{array}$ & $\begin{array}{l}\text { Optimisation problem: } \\
\text { - Objective function } \\
\text { Joint model: } \\
\text { - Contact stiffness } \\
\text { - Scaling strategy } \\
\text { (alterations performed } \\
\text { under a sensitivity analysis) }\end{array}$ & $\begin{array}{l}\text { Conclusion: Alterations slightly impacted TF contact } \\
\text { force estimations and thus model accuracy } \\
\text { Quantitative evidence: At baseline, RMSE of medial, } \\
\text { lateral, and total contact forces was } 0.28 \mathrm{BW}, 0.23 \\
\text { BW, and } 0.45 \mathrm{BW} \text {. After alteration, the maximal } \\
\text { RMSE with baseline was (1) } 0.09 \mathrm{BW},(2) 0.07 \mathrm{BW} \text {, } \\
\text { and (3) } 0.08 \mathrm{BW} \\
\text { Statistics: None }\end{array}$ \\
\hline $\begin{array}{l}\text { DeMers et } \\
\text { al. (2014) }\end{array}$ & $\mathrm{TF}$ & $\begin{array}{l}\text { Software: Opensim } \\
\text { Model: Variant of the Delp et al. (1990) model } \\
\text { DoFs: } 6 \text { pelvis, } 3 \text { hip, } 1 \mathrm{TF}, 1 \text { ankle } \\
\text { Muscular lines of action: } 46 \text { per leg } \\
\text { Muscle path: Via points } \\
\text { Optimisation: Inverse dynamics-based optimisation } \\
\text { Objective function: Sum of squared muscle activations and joint loads } \\
\text { Joint contact model: One-point rigid contact model (Steele et al., 2012) }\end{array}$ & $\begin{array}{l}\text { First edition data of the } \\
\text { Grand Challenge } \\
\text { Competition to Predict } \\
\text { In Vivo Knee Loads } \\
\text { (Fregly et al., 2012) }\end{array}$ & $\begin{array}{l}\text { Optimisation problem: } \\
\text { - Design variables: } \\
\text { (1) Muscle activations } \\
\text { (2) Joint loads }\end{array}$ & $\begin{array}{l}\text { Conclusion: A wide range of TF contact force, and } \\
\text { thus model accuracy, can be obtained depending on } \\
\text { the objective function } \\
\text { Quantitative evidence: First and second force peaks } \\
\text { during stance were (1) } 0.4 \mathrm{BW} \text { and } 1.7 \mathrm{BW} \text { larger, } \\
\text { and }(2)<0.1 \mathrm{BW} \text { and } 1.5 \mathrm{BW} \text { lower than validation } \\
\text { data } \\
\text { Statistics: None }\end{array}$ \\
\hline $\begin{array}{l}\text { Dumas et } \\
\text { al. (2012) }\end{array}$ & $\mathrm{TF}$ & $\begin{array}{l}\text { Software: Matlab } \\
\text { Model: Variant of the Delp et al. (1990) model } \\
\text { DoFs: } 6 \text { pelvis, } 3 \text { hip, } 1 \mathrm{TF}, 1 \text { ankle } \\
\text { Muscular lines of action: } 43 \text { per leg } \\
\text { Muscle path: Via points } \\
\text { Optimisation: Inverse dynamics-based optimisation } \\
\text { Objective function: Sum of squared muscle stresses } \\
\text { Joint contact model: Two-point rigid contact (Feikes et al., 2003) }\end{array}$ & $\begin{array}{l}\text { Second edition data of } \\
\text { the Grand Challenge } \\
\text { Competition to Predict } \\
\text { In Vivo Knee Loads } \\
\text { (Fregly et al., 2012) }\end{array}$ & $\begin{array}{l}\text { Joint model: } \\
\text { - Number of DoFs } \\
\text { - Passive stiffness }\end{array}$ & $\begin{array}{l}\text { Conclusion: The use of hinge joints with coupled } \\
\text { DoFs at knee and ankle, and the introduction of } \\
\text { passive joint moments, improved model accuracy } \\
\text { Quantitative evidence: No quantitative measurement } \\
\text { of model accuracy } \\
\text { Statistics: None }\end{array}$ \\
\hline $\begin{array}{l}\text { Guess et al. } \\
\quad(2014)\end{array}$ & $\mathrm{TF}$ & $\begin{array}{l}\text { Software: ADAMS and Simulink/Matlab } \\
\text { Model: Variant of the Delp et al. (1990) model } \\
\text { DoFs: } 6 \text { pelvis, } 3 \text { hip, } 6 \mathrm{TF}, 6 \mathrm{PF}, 3 \text { ankle, } 1 \text { toe } \\
\text { Muscular lines of action: } 44 \text { per leg } \\
\text { Muscle path: Via points } \\
\text { Optimisation: Forward dynamics-based optimisation }\end{array}$ & $\begin{array}{l}\text { First edition data of the } \\
\text { Grand Challenge } \\
\text { Competition to Predict } \\
\text { In Vivo Knee Loads } \\
\text { (Fregly et al., 2012) }\end{array}$ & $\begin{array}{l}\text { Optimisation } \\
\text { - PID gains }\end{array}$ & $\begin{array}{l}\text { Conclusion: A decrease of PID gain improved model } \\
\text { accuracy } \\
\text { Quantitative evidence: No quantitative measurement } \\
\text { of model accuracy } \\
\text { Statistics: None }\end{array}$ \\
\hline
\end{tabular}

Table 1 (continued) 
Article

Joint

Hast an

Piazza

(2013)

Heller et al.
(2001)

(2001)

Hip

Model: Own model based on VH project Ackerman (1998)
DoFs: 6 pelvis, 3 hip, $6 \mathrm{TF}, 3$ ankle
Muscular lines of action: 95 per leg
Muscle path: Via points
Optimisation: Inverse dynamics-based optimisation
Objective function: Sum of musculo-tendon forces
Joint contact model: One-point rigid contact model

Heller et al. Hip Joint contact model: One-point rigid contact model (2005)

Software: Custom-made software

Model: Variant of the Delp et al. (1990) model

DoFs: 6 pelvis, 3 hip, $6 \mathrm{TF}, 6 \mathrm{PF}, 1$ ankle

Muscular lines of action: 13 per leg

Muscle path: Via points and wrapping surfaces

Optimisation: Computed muscle control

Objective function: Track inverse dynamics joint angles with PID

(forward dynamics level) and sum of squared residuals between muscle

activations and normalised EMGs (inverse dynamics level)

Joint contact model: Rigid body

(20)

Knarr and

Higginson

Muscle path: Via points

Objective function: Sum of musculo-tendon forces

TF Software: Opensim
Model: Variant of the Delp et al. (1990) model
Validation dataset

Model alterations

Second edition data of Optimisation problem: the Grand Challenge

Optimisation constrain

Competition to Predict

(Fregly et al., 2012) accuracy

Conclusion: A decrease of maximum isometric forces

led to a decrease of TF contact forces and an

improvement of model accuracy

Quantitative evidence: No quantitative measurement

of model accuracy

Statistics: None
HIP98 (Data of Joint model:

subjects HSR, KWR, - Femoral anteversion

PFL, IBL) (Bergman et

al., 2001)

\section{HIP98 (Typical}

patient, averaging

procedure based o

Fourier analysis

Muscular lines of action: 95 per leg
Must 6 pelvis, 3 hip, $6 \mathrm{TF}, 3$ ankle

(Bergman et al., 2001)

Model: Variant of the Delp et al. 6 pelvis, 3 hip, 1 TF, 1 ankle, 1 toe

Muscular lines of action: 46 per leg

Muscle path: Via points

Optimisation: Inverse dynamics-based optimisation

Objective function: Sum of squared muscle activations

Joint contact model: One-point rigid contact model (Steele et al., 2012)

\section{First, second and third}

editions data of the

Grand Challenge

Competition to Predict

In Vivo Knee Loads

(Fregly et al., 2012)
Muscle model:

- Muscular redundancy
Optimisation problem:

Objective function:

(1) Sum of square

muscle activations

uniform weights

(3) And with subject-

Conclusion: An increase of femoral anteversion led to an increase of hip contact forces and a decrease in model accuracy, while a decrease of femoral

anteversion led to little or no change

Quantitative evidence: Hip superior-inferior contact force increased by up to $24 \%$ compared to validation data

Statistics: None

Conclusion: A decrease of the number of muscular lines of action led to a decrease in model accuracy Quantitative evidence: Hip superior-inferior contact force differed by $1 \%$ with baseline model and $7 \%$ with altered model compared to validation data Statistics: None

$\begin{array}{ll}\text { muscle activations } & \text { contact force was (1) 0.37-0.67 BW, (2) } 0.43 \\ \text { (2) Weighted sum with } & \text { Statistics: None }\end{array}$

Conclusion: Parameters' personalisation improved model accuracy

Quantitative evidence: RMSE range of the tota

specific weights

Optimisation constraints:

(4) Baseline with

subject-specific

musculo-tendon forces

boundaries

Statistics: None 


\section{Table 1 (continued)}

Article Joint

\begin{tabular}{|c|c|c|}
\hline $\begin{array}{l}\text { Lerner et al. } \\
\text { (2015) }\end{array}$ & $\mathrm{TF}$ & $\begin{array}{l}\text { Software: Opensim } \\
\text { Model: Variant of the Delp et al. (1990) model } \\
\text { DoFs: } 6 \text { pelvis, } 3 \text { hip, } 1 \mathrm{TF}, 1 \text { ankle, } 1 \text { subtalar } \\
\text { Muscular lines of action: } 46 \text { per leg } \\
\text { Muscle path: Via points } \\
\text { Optimisation: Inverse dynamics-based optimisation } \\
\text { Objective function: Sum of squared weighted muscle activations, with } \\
\text { subject-specific weights minimising peaks error in TF contact forces } \\
\text { (calibrated with validation data) } \\
\text { Joint contact model: Two-point rigid contact (Steele et al.. 2012) }\end{array}$ \\
\hline $\begin{array}{c}\text { Lin et al. } \\
\text { (2010) }\end{array}$ & $\mathrm{TF}$ & $\begin{array}{l}\text { Software: Matlab } \\
\text { Model: Own model of the knee and surrounding structures derived } \\
\text { from medical imaging } \\
\text { DoFs: } 6 \mathrm{TF}, 6 \mathrm{PF} \\
\text { Muscular lines of action: } 11 \\
\text { Muscle path: Via points } \\
\text { Optimisation: Inverse dynamics-based optimisation } \\
\text { Objective function: Sum of squared muscle activations } \\
\text { Joint contact model: Surrogate contact modelling (Lin et al., 2009) }\end{array}$ \\
\hline
\end{tabular}

: Inverse dynamics-based optimisation

Joint contact model: Surrogate contact modelling (Lin et al., 2009)

\section{Validation dataset Model alterations}

Second edition data of Joint model:

he Grand Challenge - Knee alignment

Competition to Predict - Contact points

In Vivo Knee Loads

(Fregly et al., 2012)

(1) Baseline

(2) Knee alignment and

$\begin{array}{ll}\text { contact points } & \text { alteration) } \\ \text { (3) Knee alignment only } & \text { Statistics: } 95 \% \text { confidence intervals reported to }\end{array}$

(4) Contact points only determine if statistically significant differences exists at first and second TF contact force peaks

Gait data collected on Optimisation problem:

an adult male with - Design variables:

instrumented knee

implant

Zhao et al. (2007) accuracy

Conclusion: Improvement of knee alignment and contact points location increased model accuracy Quantitative evidence: RMSE of the total contact force was (1) $0.51 \mathrm{BW}$, (2) $0.33 \mathrm{BW}$, (3) $0.37 \mathrm{BW}$, Statistics: $95 \%$ confidence intervals reported
determine if statistically significant differen

(1) Muscle activations

(2) Compressive contact forces

- Optimisation constraints:

(a) F/E moment residual (b) F/E moment and $A / P$ force residuals

\begin{tabular}{|c|c|c|}
\hline $\begin{array}{l}\text { Lund et al. } \\
\text { (2015) }\end{array}$ & $\mathrm{TF}$ & $\begin{array}{l}\text { Software: Anybody } \\
\text { Model: Variant of the Klein Horsman et al. (2007) model } \\
\text { DoFs: } 6 \text { pelvis, } 3 \text { hip, } 1 \mathrm{TF}, 1 \mathrm{PF}, 2 \text { ankle } \\
\text { Muscular lines of action: } 159 \text { per leg } \\
\text { Muscle path: Via points and wrapping surfaces } \\
\text { Optimisation: Inverse dynamics-based optimisation } \\
\text { Objective function: Sum of cubed muscle activations } \\
\text { Joint contact model: One-point rigid contact }\end{array}$ \\
\hline $\begin{array}{l}\text { Lundberg et } \\
\text { al. (2012) }\end{array}$ & $\mathrm{TF}$ & $\begin{array}{l}\text { Software: Matlab } \\
\text { Model: Knee model, variant of the Delp et al. (1990) model } \\
\text { DoFs: } 6 \mathrm{TF} \\
\text { Muscular lines of action: } 15 \text { (reduced to 3) } \\
\text { Muscle path: Via points } \\
\text { Optimisation: Not used. A model reduction is applied to cancel } \\
\text { muscular redundancy, and equations governing dynamic equilibrium } \\
\text { and relationship between medial and lateral contact forces are solved } \\
\text { Objective function: Not used } \\
\text { Joint contact model: Linear function of the varus-valgus moment }\end{array}$ \\
\hline
\end{tabular}

\section{Impact of the alterations on joint contact force} (4) $0.45 \mathrm{BW}$ (peak errors also reported for each

(c) $F / E$ moment and $I / E$
(orce residuals moment residuals (d) Both

(baseline: 1a)

Third edition data of Joint model: the Grand Challenge - Markers' placement Competition to Predict - Scaling strategy: In Vivo Knee Loads (1) Linear scaling (Fregly et al., 2012) (baseline)

(2) Anatomical scaling

(3) Kinematic scaling

Gait data collected on four adults with instrumented knee implant Mundermann et al. (2008)

\section{Optimisation problem:} - Optimisation constraints: muscle activation boundaries (alterations performed under a sensitivity analysis)
Conclusion: The introduction of residual loads on joint forces and/or moments improved model accuracy. In most cases, the objective functions provided similar results for lateral contact, while (2) provide a better model accuracy when A/P force residual was used as constraint

Quantitative evidence: RMSE were (1a) 0.17 and $0.51 \mathrm{BW},(1 \mathrm{~b}) 0.32$ and $0.37 \mathrm{BW},(1 \mathrm{c}) 0.23$ and 0.35 $\mathrm{BW}$, (1d) 0.26 and $0.35 \mathrm{BW},(2 \mathrm{a}) 0.20$ and $0.45 \mathrm{BW}$, (2b) 0.12 and $0.40 \mathrm{BW},(2 \mathrm{c}) 0.24$ and $0.39 \mathrm{BW}$, and (2d) 0.24 and $0.41 \mathrm{BW}$, respectively for medial and lateral contact forces Statistics: None

Conclusion: Kinematic scaling (3) provided the most accurate TF total contact force and was the method the less affected by marker placements errors Quantitative evidence: RMSE of the total contact force was (1) $0.36 \mathrm{BW}$, (2) $0.64 \mathrm{BW}$, and (3) 0.28 BW

Statistics: Monte Carlo simulations to study the effect of variations in manual markers placements Conclusion: The alterations introduced variability in $\mathrm{TF}$ contact forces estimations impacting model accuracy

Quantitative evidence: RMSE averaged across trials of the total contact force ranged between 0 and 0.09 $\mathrm{BW}$ at the first force peak, $-0.03 \mathrm{BW}$ and $-0.30 \mathrm{BW}$ at the local minimum at mid-stance, and $0 \mathrm{BW}$ and $0.10 \mathrm{BW}$ at the second force peak, for patients without gait deviation (Subjects 1, 2 and 4). Values of an adjusted $\mathrm{R}^{2}$ are also given Statistics: None 


\section{Table 1 (continued)}

\begin{tabular}{|c|c|c|c|c|c|}
\hline Article & Joint & Generic musculoskeletal model & Validation dataset & Model alterations & $\begin{array}{l}\text { Impact of the alterations on joint contact force } \\
\text { accuracy }\end{array}$ \\
\hline $\begin{array}{l}\text { Lundberg } \\
\text { et al. } \\
(2013)\end{array}$ & $\mathrm{TF}$ & $\begin{array}{l}\text { Software: Matlab } \\
\text { Model: Knee model, variant of the Delp et al. (1990) model } \\
\text { DoFs: } 6 \mathrm{TF} \\
\text { Muscular lines of action: } 15 \text { (reduced to 3) } \\
\text { Muscle path: Via points } \\
\text { Optimisation: Not used. A model reduction is applied to cancel } \\
\text { muscular redundancy, and equations governing dynamic equilibrium } \\
\text { and relationship between medial and lateral contact forces are solved } \\
\text { Objective function: Not used } \\
\text { Joint contact model: Linear function of the varus-valgus moment }\end{array}$ & $\begin{array}{l}\text { Third edition data of } \\
\text { the Grand Challenge } \\
\text { Competition to Predict } \\
\text { In Vivo Knee Loads } \\
\text { (Fregly et al., 2012) }\end{array}$ & $\begin{array}{l}\text { Joint model: } \\
\text { - Number of DoFs } \\
\text { - Medial-lateral contact } \\
\text { force ratio } \\
\text { - Passive stiffness }\end{array}$ & $\begin{array}{l}\text { Conclusion: The alterations improved the model } \\
\text { accuracy in estimating medial and lateral contact } \\
\text { forces, while keeping a similar total contact force } \\
\text { Quantitative evidence: At baseline, RMSE of medial, } \\
\text { lateral, and total contact forces was } 0.38 \mathrm{BW}, 0.32 \\
\text { BW, and } 0.37 \mathrm{BW} \text {. After alterations, it was } 0.31 \mathrm{BW} \text {, } \\
0.13 \mathrm{BW} \text {, and } 0.38 \mathrm{BW} \\
\text { Statistics: None }\end{array}$ \\
\hline $\begin{array}{c}\text { Manal and } \\
\text { Buchanan } \\
\text { (2013) }\end{array}$ & $\mathrm{TF}$ & $\begin{array}{l}\text { Software: SIMM } \\
\text { Model: Variant of the Delp et al. (1990) model } \\
\text { DoFs: } 6 \text { pelvis, } 3 \text { hip, } 3 \text { TF, } 3 \text { ankle } \\
\text { Muscular lines of action: } 12 \\
\text { Muscle path: Via points } \\
\text { Optimisation: EMG-driven } \\
\text { Objective function: Sum of squared differences between estimated } \\
\text { and inverse dynamic-based joint moments } \\
\text { Joint contact model: Two-point rigid contact }\end{array}$ & $\begin{array}{l}\text { Third edition data of } \\
\text { the Grand Challenge } \\
\text { Competition to Predict } \\
\text { In Vivo Knee Loads } \\
\text { (Fregly et al., 2012) }\end{array}$ & $\begin{array}{l}\text { Joint model: } \\
\text { - Contact points (tibial } \\
\text { plateau width and } \\
\text { points' location) } \\
\text { Muscle model: } \\
\text { - Muscle parameters } \\
\text { (EMG-driven } \\
\text { parameters) }\end{array}$ & $\begin{array}{l}\text { Conclusion: An iterative process of parameters' } \\
\text { variations allowed to improve the model accuracy } \\
\text { Quantitative evidence: At baseline, RMSE of medial } \\
\text { and lateral contact forces was } 0.28 \mathrm{BW} \text { and } 0.18 \mathrm{BW} \text {. } \\
\text { After alterations, it was } 0.16 \mathrm{BW} \text { and } 0.22 \mathrm{BW} . \mathrm{R}^{2} \\
\text { and peak difference are also given } \\
\text { Statistics: None }\end{array}$ \\
\hline $\begin{array}{l}\text { Modenese } \\
\text { et al. } \\
(2011)\end{array}$ & Hip & $\begin{array}{l}\text { Software: Opensim } \\
\text { Model: Variant of the Klein Horsman et al. (2007) model } \\
\text { DoFs: } 6 \text { pelvis, } 3 \text { hip, } 1 \mathrm{TF}, 1 \text { ankle } \\
\text { Muscular lines of action: } 163 \text { per leg } \\
\text { Muscle path: Via points and wrapping surfaces } \\
\text { Optimisation: Inverse dynamics-based optimisation } \\
\text { Objective function: Sum of muscle stresses at power p } \\
\text { Joint contact model: One-point rigid contact }\end{array}$ & $\begin{array}{l}\text { HIP98 (Data of } \\
\text { subjects HSR, KWR, } \\
\text { PFL, IBL) (Bergman et } \\
\text { al., 2001) }\end{array}$ & $\begin{array}{l}\text { Optimisation problem: } \\
\text { - Objective function: } \\
\text { (1) Power } \mathrm{p}=1 \\
\text { (2) Power } \mathrm{p}=2 \\
\text { (3) Power } \mathrm{p}=3 \\
\text { (4) Power } \mathrm{p}=5 \\
\text { (5) Power } \mathrm{p}=10 \\
\text { (6) Power } \mathrm{p}=15\end{array}$ & $\begin{array}{l}\text { Conclusion: A quadratic objective function provided } \\
\text { a better model accuracy than other powers in terms of } \\
\text { hip contact force and musculo-tendon forces } \\
\text { estimation } \\
\text { Quantitative evidence: RMSE averaged range across } \\
\text { subjects was (1) } 0.25-0.47 \mathrm{BW},(2) 0.23-0.52 \mathrm{BW},(3) \\
0.33-0.66 \mathrm{BW} \text {, (4) } 0.50-0.91 \mathrm{BW},(5) 1.77-2.85 \mathrm{BW} \text {, } \\
\text { (6) } 2.88-4.52 \mathrm{BW} \\
\text { Statistics: None }\end{array}$ \\
\hline $\begin{array}{l}\text { Modenese } \\
\text { et al. } \\
(2013)\end{array}$ & Hip & $\begin{array}{l}\text { Software: Opensim } \\
\text { Model: Variant of the Klein Horsman et al. (2007) model } \\
\text { DoFs: } 6 \text { femur, } 1 \mathrm{TF}, 1 \text { ankle } \\
\text { Muscular lines of action: } 163 \text { per leg } \\
\text { Muscle path: Via points and wrapping surfaces } \\
\text { Optimisation: Inverse dynamics-based optimisation } \\
\text { Objective function: Sum of squared muscle stresses }\end{array}$ & $\begin{array}{l}\text { HIP98 (Data of } \\
\text { subjects HSR, KWR, } \\
\text { PFL, IBL) (Bergman et } \\
\text { al., 2001) }\end{array}$ & $\begin{array}{l}\text { Optimisation problem: } \\
\text { - Design variables: } \\
\text { (1) Without reserve } \\
\text { actuators (baseline) } \\
\text { (2) With reserve } \\
\text { actuators }\end{array}$ & $\begin{array}{l}\text { Conclusion: The introduction of reserve actuators } \\
\text { improved model accuracy, showing a need for } \\
\text { improving the muscular geometry (i.e. lever arms) } \\
\text { Quantitative evidence: RMSE was (1) } 0.59 \mathrm{BW},(2) \\
\text { 0.18 BW } \\
\text { Statistics: None }\end{array}$ \\
\hline
\end{tabular}




\section{Table 1 (continued)}

Article Joint

\begin{tabular}{|c|c|c|}
\hline $\begin{array}{l}\text { Moissenet } \\
\text { et al. } \\
(2014)\end{array}$ & $\mathrm{TF}$ & $\begin{array}{l}\text { Software: Matlab } \\
\text { Model: Variant of the Delp et al. (1990) model } \\
\text { DoFs: } 6 \text { pelvis, } 3 \text { hip, } 1 \mathrm{TF}, 1 \mathrm{PF}, 1 \text { ankle } \\
\text { Muscular lines of action: } 43 \text { per leg } \\
\text { Muscle path: Via points } \\
\text { Optimisation: Inverse dynamics-based optimisation } \\
\text { Objective function: Sum of squared musculo-tendon forces } \\
\text { Joint contact model: Two-point rigid contact (Feikes et al., 2003) }\end{array}$ \\
\hline $\begin{array}{c}\text { Moissenet } \\
\text { et al. } \\
(2016)\end{array}$ & $\mathrm{TF}$ & $\begin{array}{l}\text { Software: Matlab } \\
\text { Model: Variant of the Delp et al. (1990) model } \\
\text { DoFs: } 6 \text { pelvis, } 3 \text { hip, } 1 \mathrm{TF}, 1 \mathrm{PF}, 1 \text { ankle } \\
\text { Muscular lines of action: } 43 \text { per leg } \\
\text { Muscle path: Via points } \\
\text { Optimisation: Inverse dynamics-based optimisation } \\
\text { Objective function: Sum of squared and weighted musculo-tendon } \\
\text { forces and joint contact, ligament, and bone forces } \\
\text { Joint contact model: Two-point rigid contact (Feikes et al., 2003) }\end{array}$ \\
\hline $\begin{array}{c}\text { Navacchia } \\
\text { et al. } \\
\text { (2016) }\end{array}$ & $\mathrm{TF}$ & $\begin{array}{l}\text { Software: Opensim } \\
\text { Model: Variant of the Delp et al. (1990) model } \\
\text { DoFs: } 6 \text { pelvis, } 3 \text { hip, } 2 \mathrm{TF}, 1 \text { ankle } \\
\text { Muscular lines of action: } 92 \text { per leg } \\
\text { Muscle path: Via points } \\
\text { Optimisation: Inverse dynamics-based optimisation } \\
\text { Objective function: Sum of squared muscle activations } \\
\text { Joint contact model: One-point rigid contact model (Steele et al., } \\
\text { 2012) }\end{array}$ \\
\hline $\begin{array}{l}\text { Serrancoli } \\
\text { et al. } \\
(2016)\end{array}$ & $\mathrm{TF}$ & $\begin{array}{l}\text { Software: Opensim } \\
\text { Model: Variant of the Arnold et al. (2010) model } \\
\text { DoFs: } 6 \text { pelvis, } 3 \text { hip, } 6 \mathrm{TF}, 6 \mathrm{PF}, 2 \text { ankle } \\
\text { Muscular lines of action: } 44 \text { per leg } \\
\text { Muscle path: Via points and wrapping surfaces } \\
\text { Optimisation: Inverse dynamics-based optimisation } \\
\text { Objective function: Sum of squared muscle activations plus sum of } \\
\text { six squared reserve activations } \\
\text { Joint contact model: Validated regression equation converting } \\
\text { superior-inferior force and varus-valgus moment to medial and lateral } \\
\text { contact forces (Fregly et al., 2012) }\end{array}$ \\
\hline
\end{tabular}

\section{Validation datase}

First, second, third and fourth edition data of

the Grand Challenge

Co Grand Challenge

Competition to Predict

In Vivo Knee Loads
(Fregly et al., 2012)

Sixth edition data of

the Grand Challenge

Competition to Predict

In Vivo Knee Loads

(Fregly et al., 2012)

Data of three undefined subjects of the Grand Challenge Competitio to Predict In Vivo

Knee Loads (Fregly et al., 2012)

\section{Fourth edition data of the Grand Challenge Competition to Predict \\ In Vivo Knee Loads}

(Fregly et al., 2012)

\section{Model alterations}

Optimisation problem:

(1) Musculo-tendon forces (baseline)

(2) Musculo-tendon forces and joint contact, ligament, and bone forces

Muscle model:

- Muscular redundancy:

(1) 43 lines of action

(baseline)

2) 163 lines of action (variant of the Klein Horsman et al. (2007) model)

\section{Joint model:}

- Markers' placement

- Knee alignment

- Inertial parameters

Muscle model:

- Muscle geometry

- Muscle parameters

(alterations performed under a sensitivity

analysis)

Muscle model:

- Muscle geometry

Muscle parameters

Variations are manage

though a two-level

optimisation

(1) Without tracking

validation data

(baseline)

(2) By tracking

validation data

\section{Impact of the alterations on joint contact force} accuracy

Conclusion: The introduction of joint contact,

ligament, and bone forces in the muscular redundancy problem improved model accuracy

Quantitative evidence: RMSE ranges of medial and lateral contact forces across subjects were (1) 0.91 $1.39 \mathrm{BW}$ and $0.44-0.81 \mathrm{BW},(2) 0.31-0.50 \mathrm{BW}$ and 0.22-0.43 BW

Statistics: None

Conclusion: An increase of muscular redundancy

modified medial-lateral contact forces balance but did not impact the accuracy of the model to estimate total contact force

Quantitative evidence: RMSE of medial, lateral, an total contact forces was (1) $0.65 \mathrm{BW}, 0.45 \mathrm{BW}$, and $0.70 \mathrm{BW}$, (2) 0.26 BW, 0.63 BW, and 0.77 BW

Statistics: None

\section{Conclusion: Each alteration impacted the model} accuracy

Quantitative evidence: At baseline, RMSE of the total contact force ranged between $0.30 \mathrm{BW}$ and $0.35 \mathrm{BW}$. After alteration, no quantitative measurement of model accuracy is reported

Statistics: A Monte-Carlo simulation was conducted. The validation data were within the predicted 5-95\% confidence bounds for $77 \%, 83 \%$, and $75 \%$ of stance phase, respectively.

Conclusion: Tracking validation data improved model accuracy

Quantitative evidence: RMSE of the medial, lateral and total contact forces averaged across trials was (1) $0.51 \mathrm{BW}, 0.55 \mathrm{BW}$, and $0.88 \mathrm{BW}$, (2) $0.08 \mathrm{BW}, 0.09$ $\mathrm{BW}$, and $0.15 \mathrm{BW}$

Statistics: Two-tailed t-test were used to evaluate Statistics: Two-tailed t-test were used to e
statistical significant differences in results 


\section{Table 1 (continued)}

\begin{tabular}{|c|c|c|c|c|c|}
\hline $\begin{array}{l}\text { Steele et } \\
\text { al. (2012) }\end{array}$ & $\mathrm{TF}$ & $\begin{array}{l}\text { Software: Opensim } \\
\text { Model: Variant of the Delp et al. (1990) model } \\
\text { DoFs: } 6 \text { pelvis, } 3 \text { hip, } 1 \mathrm{TF}, 1 \text { ankle } \\
\text { Muscular lines of action: } 92 \text { per leg } \\
\text { Muscle path: Via points } \\
\text { Optimisation: Inverse dynamics-based optimisation } \\
\text { Objective function: Sum of weighted squared muscle activations } \\
\text { Joint contact model: One-point rigid contact model }\end{array}$ & $\begin{array}{l}\text { First edition data of the } \\
\text { Grand Challenge } \\
\text { Competition to Predict } \\
\text { In Vivo Knee Loads } \\
\text { (Fregly et al., 2012) }\end{array}$ & $\begin{array}{l}\text { Optimisation problem: } \\
\text { - Optimisation weights }\end{array}$ & $\begin{array}{l}\text { Conclusion: Using an iterative process, the authors } \\
\text { were able to improve model accuracy by finding the } \\
\text { best set of optimisation weights } \\
\text { Quantitative evidence: At baseline, no quantitative } \\
\text { measurement of model accuracy is reported. After } \\
\text { alteration, RMSE of total contact force was } 0.28 \mathrm{BW} \\
\text { Statistics: None }\end{array}$ \\
\hline $\begin{array}{l}\text { Thelen et } \\
\text { al. (2014) }\end{array}$ & $\mathrm{TF}$ & $\begin{array}{l}\text { Software: Opensim } \\
\text { Model: Variant of the Arnold et al. (2010) model } \\
\text { DoFs: } 6 \text { pelvis, } 3 \text { hip, } 6 \mathrm{TF}, 6 \mathrm{PF}, 2 \text { ankle } \\
\text { Muscular lines of action: } 44 \text { per leg } \\
\text { Muscle path: Via points and wrapping surfaces } \\
\text { Optimisation: Computed muscle control } \\
\text { Objective function: Track joint angles computed during inverse } \\
\text { dynamics with PID (forward dynamics level) and sum of weighted } \\
\text { squared muscle activations (inverse dynamics level) } \\
\text { Joint contact model: One-point rigid contact model }\end{array}$ & $\begin{array}{l}\text { Fourth edition data of } \\
\text { the Grand Challenge } \\
\text { Competition to Predict } \\
\text { In Vivo Knee Loads } \\
\text { (Fregly et al., 2012) }\end{array}$ & $\begin{array}{l}\text { Joint model: } \\
\text { - Knee alignment }\end{array}$ & $\begin{array}{l}\text { Conclusion: Adjustment of knee alignment modified } \\
\text { medial-lateral contact forces balance but did not } \\
\text { impact the accuracy of the model to estimate total } \\
\text { contact force } \\
\text { Quantitative evidence: At baseline, RMSE of medial, } \\
\text { lateral, and total contact forces was } 0.26 \mathrm{BW}, 0.42 \\
\text { BW, and } 0.51 \mathrm{BW} \text {. After alteration, no quantitative } \\
\text { measurement of model accuracy is reported } \\
\text { Statistics: None }\end{array}$ \\
\hline $\begin{array}{l}\text { Walter et } \\
\text { al. (2014) }\end{array}$ & $\mathrm{TF}$ & $\begin{array}{l}\text { Software: Opensim } \\
\text { Model: Variant of the Arnold et al. (2010) model } \\
\text { DoFs: } 6 \text { pelvis, } 3 \text { hip, } 6 \text { TF, } 6 \text { PF, } 2 \text { ankle } \\
\text { Muscular lines of action: } 44 \text { per leg } \\
\text { Muscle path: Via points and wrapping surfaces } \\
\text { Optimisation: Mixed optimisation combining inverse skeletal } \\
\text { dynamics and forward muscle activation and contraction dynamics } \\
\text { Objective function: Sum of squared differences between estimated } \\
\text { and inverse dynamic-based joint moments } \\
\text { Joint contact model: Validated regression equation converting } \\
\text { superior-inferior force and varus-valgus moment to medial and lateral } \\
\text { contact forces (Fregly et al., 2012) }\end{array}$ & $\begin{array}{l}\text { Third edition data of } \\
\text { the Grand Challenge } \\
\text { Competition to Predict } \\
\text { In Vivo Knee Loads } \\
\text { (Fregly et al., 2012) }\end{array}$ & $\begin{array}{l}\text { Optimisation problem: } \\
\text { - Use of synergies: } \\
\text { (1) Independent } \\
\text { controls without EMG } \\
\text { tracking (baseline) } \\
\text { (2) Independent } \\
\text { controls with EMG } \\
\text { tracking } \\
\text { (3) Synergy controls } \\
\text { without EMG tracking } \\
\text { (4) Synergy controls } \\
\text { with EMG tracking }\end{array}$ & $\begin{array}{l}\text { Conclusion: EMG tracking decreased model accuracy } \\
\text { when using synergy controls, but increased model } \\
\text { accuracy when using independent controls (EMG } \\
\text { tracking is then critical). However, synergy controls } \\
\text { always produced more accurate contact forces } \\
\text { Quantitative evidence: RMSE of medial and lateral } \\
\text { contact forces averaged across was (1) } 0.29 \mathrm{BW},(2) \\
0.20 \mathrm{BW} \text {, (3) } 0.15 \mathrm{BW} \text {, and (4) } 0.19 \mathrm{BW} \text {. } \\
\text { Statistics: None }\end{array}$ \\
\hline $\begin{array}{l}\text { Zhang et } \\
\text { al. (2015) }\end{array}$ & Hip & $\begin{array}{l}\text { Software: Anybody } \\
\text { Model: Variant of the Klein Horsman et al. (2007) model } \\
\text { DoFs: } 6 \text { pelvis, } 6 \text { hip, } 1 \mathrm{TF}, 1 \text { ankle, } 1 \text { subtalar } \\
\text { Muscular lines of action: } 163 \text { per leg } \\
\text { Muscle path: Via points and wrapping surfaces } \\
\text { Optimisation: Inverse dynamics-based optimisation } \\
\text { Objective function: Sum of squared musculo-tendon forces } \\
\text { Joint contact model: Force dependent kinematic (Andersen \& } \\
\text { Rasmusen 2011) }\end{array}$ & $\begin{array}{l}\text { HIP98 (Data of } \\
\text { subjects HSR, KWR, } \\
\text { IBL) (Bergman et al., } \\
\text { 2001) }\end{array}$ & $\begin{array}{l}\text { Optimisation problem: } \\
\text { (1) Objective function } \\
\text { Joint model: } \\
\quad \text { (2) Contact stiffness } \\
\text { Muscle model: } \\
\text { (3) Muscle geometry } \\
\text { (alterations performed } \\
\text { under a sensitivity } \\
\text { analysis) }\end{array}$ & $\begin{array}{l}\text { Conclusion: Only alteration of the objective function } \\
\text { had a marked impact on accuracy. } \\
\text { Quantitative evidence: At baseline, RMSE averaged } \\
\text { across subjects was } 0.45 \mathrm{BW} \text {. After alteration, the } \\
\text { maximal RMSE with baseline was (1) } 0.18 \mathrm{BW},(2) \\
0.03 \mathrm{BW} \text {, and (3) } 0.05 \mathrm{BW} \\
\text { Statistics: None }\end{array}$ \\
\hline
\end{tabular}


Figure 1

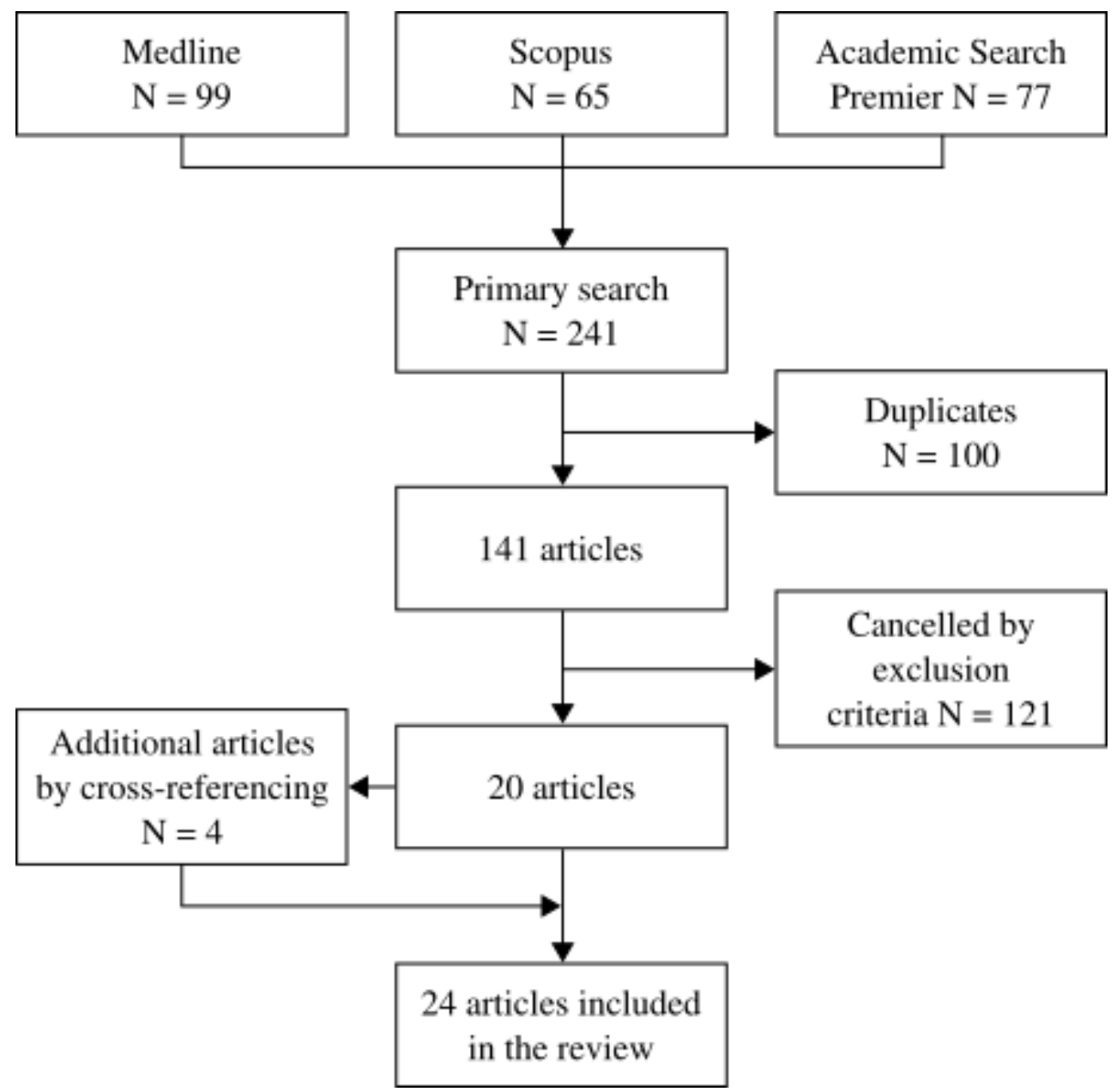


Figure 2

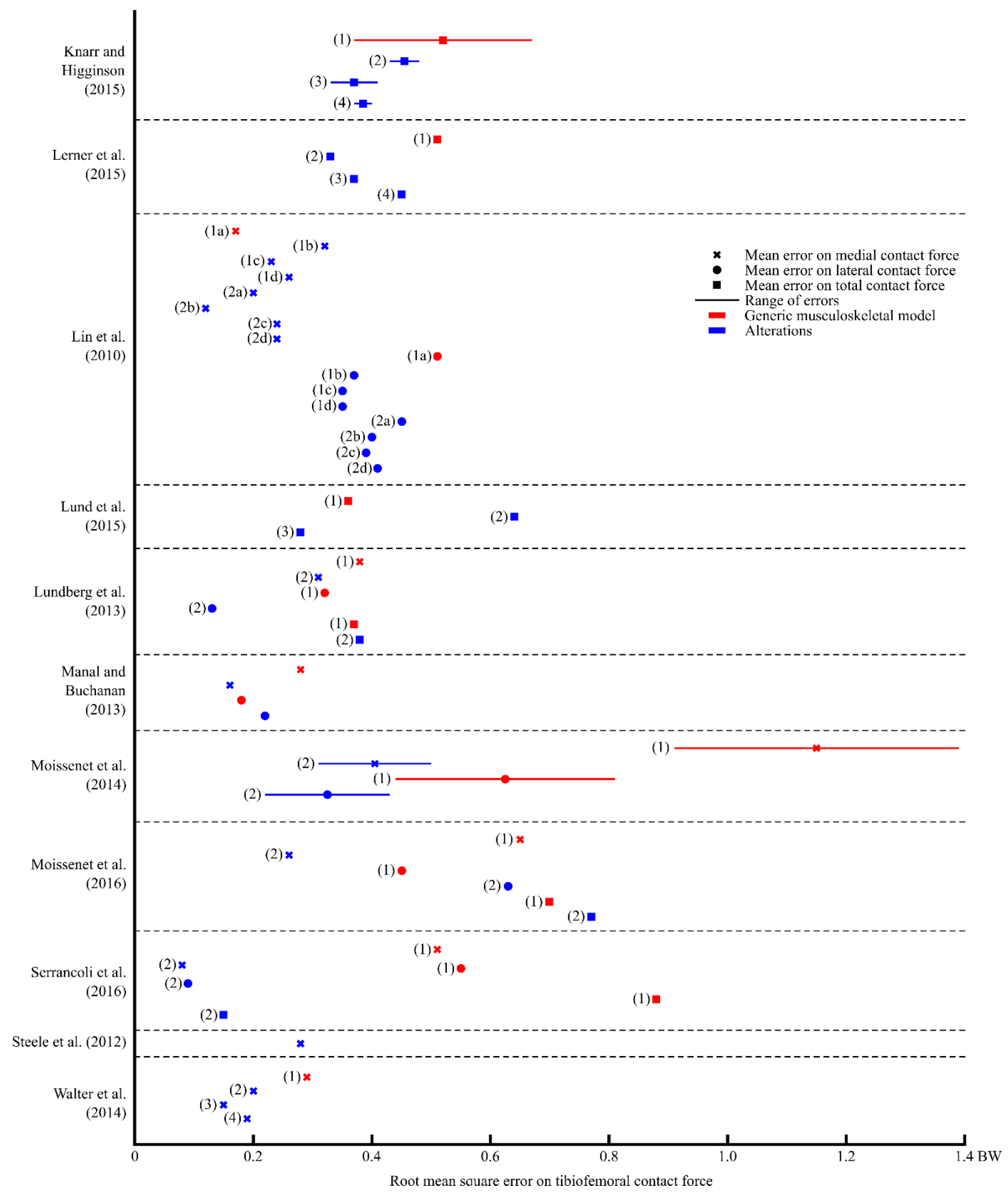


Figure 3

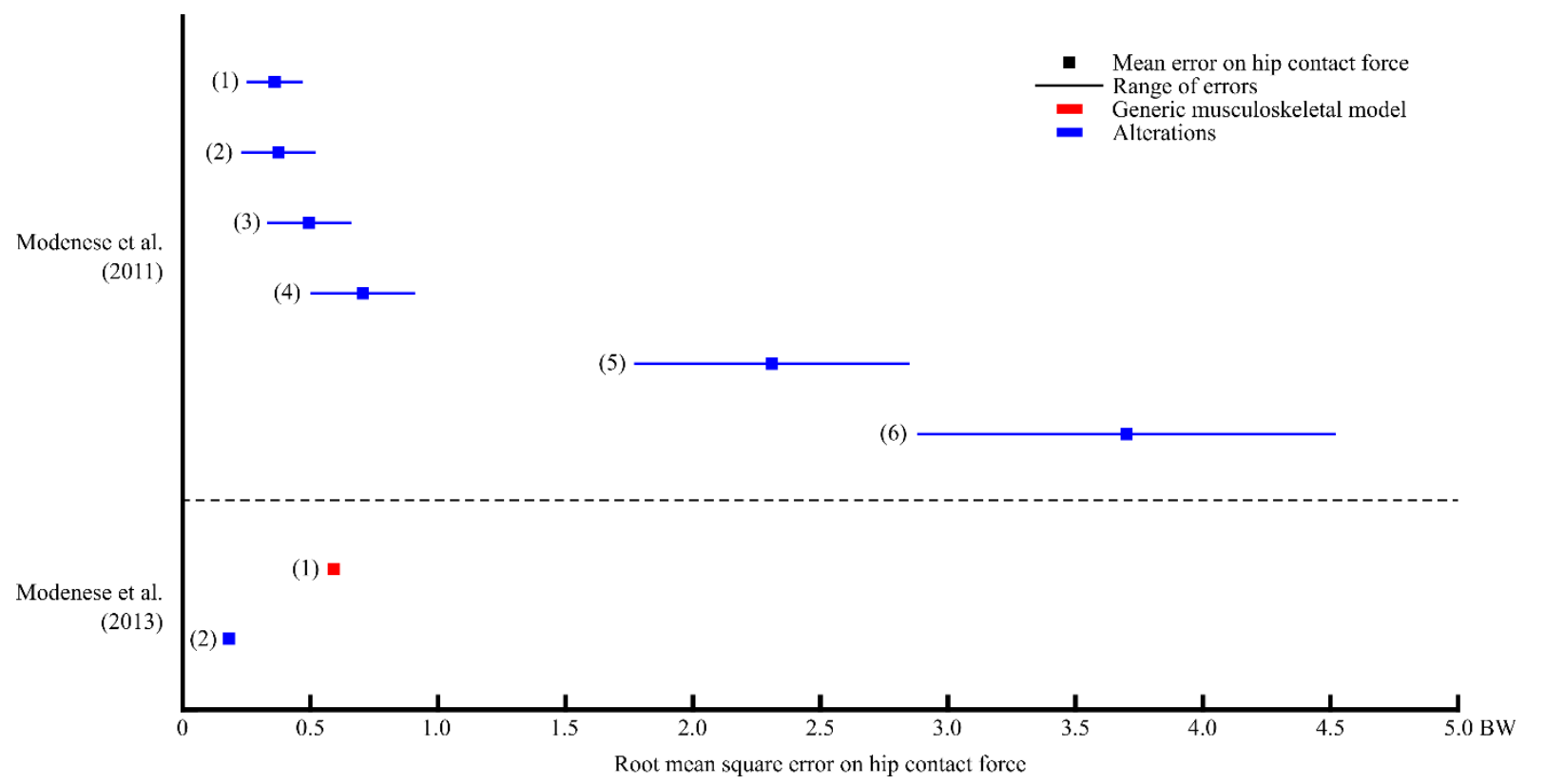

